\title{
Perinatal Iron Deficiency: Implications for Mothers and Infants
}

\author{
Sandra E. Juul ${ }^{a}$ Richard J. Derman ${ }^{b}$ Michael Auerbach ${ }^{c}$ \\ ${ }^{a}$ Department of Pediatrics, University of Washington, Seattle, WA, USA; ${ }^{b}$ Global Affairs, Thomas Jefferson University, \\ Philadelphia, PA, USA; ' Georgetown University School of Medicine, Washington, DC, USA
}

\section{Keywords}

Parenteral iron · Iron insufficiency · Iron deficiency

\begin{abstract}
Iron deficiency, with or without anemia, is common in pregnant women. In fact, nearly $30 \%$ of reproductive-age women are anemic worldwide, and anemia in pregnancy has an estimated global prevalence of $38 \%$. Severe anemia can substantially increase the risk of maternal mortality, and can adversely affect fetal development. In this review, we examine the available data regarding epidemiology and consequences of iron deficiency in mothers and infants, current treatment strategies, and make recommendations for screening and treatment of iron deficiency anemia in gravidas and neonates.

(c) 2019 S. Karger AG, Basel
\end{abstract}

\section{Introduction}

A systematic analysis of global trends in prevalence of anemia resulted in 2011 estimates of 32 million anemic pregnant women and 273 million anemic children [1].
Anemia remains a significant global health problem, especially in low- and middle-income countries where up to $50 \%$ of pregnant women are diagnosed with anemia. While iron deficiency (ID) is not the only cause of anemia, it is the most common contributor. Strategies to reduce anemia among pregnant women often prove ineffective, and a recent publication utilizing data from a WHO survey reported that severe anemia can substantially increase the risk of maternal mortality [2]. Thus, we believe current recommendations for screening and treatment of ID anemia (IDA) in gravidas and neonates require revision, and we further believe failure to address the use of intravenous iron in both populations represents an unmet clinical need.

\section{Rationale}

ID during pregnancy is common in the United States and globally. Nearly $30 \%$ of reproductive-age women are anemic worldwide, and anemia in pregnancy has an estimated global prevalence of 38\% [3]. Thus, we will review consequences of ID for mother and child, and options for correcting ID. While prospective studies proving the benefits of routine screening and supplementation are sparse, ample evidence-based reports indicate that ID in mothers

\section{KARGER}

(c) 2019 S. Karger AG, Basel

E-Mail karger@karger.com

www.karger.com/neo
Michael Auerbach, MD

5233 King Avenue \#308

Baltimore, MD 21237 (USA)

E-Mail mauerbachmd@abhemonc.com 
and infants causes significant morbidity. Animal models provide convincing evidence that the absence of iron during critical windows of brain development results in alterations in brain metabolism, neurotransmission, epigenetics, and myelination that persist throughout development [4]. Fetal, neonatal, and childhood brain growth and development require iron, with deficiencies resulting in adverse effects on myelination, neurotransmitter synthesis and brain programming. Published evidence reports that when iron is severely limited in the neonate, the available iron is shunted preferentially to red blood cells, at the expense of brain, heart, and muscle [4-6]. Low maternal serum ferritin concentrations are associated with ID in neonates [7], which has been associated with a statistically significant increment in both cognitive and behavioral abnormalities [8] that is long lasting, detectable up to 19 years of age [9]. There is strong evidence that in 6- to 24-month-old infants with IDA there is increased risk for poorer cognitive, motor, social-emotional, and neurophysiologic development [10-12].

In addition to direct effects on brain development, iron-deficient mothers experience a twofold increased incidence of preterm birth, and a threefold increase in lowbirth-weight and small for gestational age infants, all of which are associated with poorer neurodevelopmental outcomes. Maternal IDA is associated with increased risk for cesarean delivery, transfusion, perinatal bleeding, preeclampsia, placental abruption, poor maternal thyroid status, poor wound healing, cardiac failure, and even death $[11,13,14]$.

\section{Results}

\section{ID in Pregnancy}

Iron requirements dramatically increase in pregnancy to accommodate an expanding red cell volume, growing fetus, and placenta plus any anticipated or unanticipated blood loss at delivery, especially with caesarean delivery [15]. Scholl [16] reported that iron requirements in pregnancy may exceed 1,000 mg with 500 required for red cell expansion, 300-350 for the developing fetus and placenta with variable losses at delivery. Surprisingly, it is uncommon for pregnant women to be checked for ID unless anemic, and low hemoglobin concentration alone may miss up to $55 \%$ of ID gravidas when other iron parameters are not added to screening laboratory tests [17]. Screening for neonatal ID using the complete blood count is insensitive to mild or moderate ID [18]. Permanent IDrelated neurodevelopmental delays might occur well be- fore anemia is present. Ferritin, zinc protoporphyrin to heme ratios, and reticulocyte hemoglobin content are more sensitive tests in the neonate [19-22].

The diagnosis of maternal ID can be made with readily available, inexpensive blood tests which should include a complete blood count, serum iron, total iron binding capacity, percent transferrin saturation (Fe/ TIBC), and serum ferritin. The WHO guidelines for anemia during pregnancy define a hemoglobin level of $<11$ $\mathrm{g} / \mathrm{dL}$ at any time [23]. The Centers for Disease Control and Prevention (CDC) defines anemia as a hemoglobin $<$ $11 \mathrm{~g} / \mathrm{dL}$ during the first and third trimesters and $<10.5 \mathrm{~g} /$ $\mathrm{dL}$ in the second [12]. Even in the absence of anemia, ID is considered present with transferrin saturations of < $20 \%$ and/or ferritins $<30 \mathrm{ng} / \mathrm{mL}$. ID may be suspected, with or without anemia, when specific symptoms such as pagophagia (ice craving), other forms of pica, or restless legs syndrome are present. Figure 1 shows examples of physical findings of iron depletion which include cracking of the corners of the mouth (angular cheilosis), horizontal lines in the finger nails (koilonychia), and depapillation of the tongue. Oral iron remains frontline therapy. When effective and well tolerated, it is inexpensive and convenient. However, gastrointestinal side effects are common and nonadherence high. Oral iron exacerbates constipation which is common during pregnancy due to high progesterone levels which slow bowel transit, and the enlarging uterus pressing posteriorly on the rectum. In the third trimester, absorption decreases, resulting in poor efficacy, prompting practitioners to increase the frequency of administration. The likely ineffectiveness of this strategy is supported by recent evidence reporting oral iron ingestion raises serum hepcidin, decreasing absorption and utilization [24]. Supporting this contention is a prospective study showing increased absorption of radiolabeled ferrous sulfate with alternate day compared to daily or twice daily ingestion [25].

Intravenous iron has been shown to be uniformly safe and effective, yet guidelines vary greatly. In the 2008 ACOG Practice Bulletin, intravenous iron is recommended in the "rare patient who cannot tolerate or will not take modest doses of oral iron" with the caveat that patients with severe malabsorption may benefit from parenteral iron [26]. In contradistinction, the 2012 United Kingdom guidelines state that "parenteral iron should be considered from the second trimester onwards and during the postpartum period for women with confirmed ID who fail to respond to, or are intolerant of, oral iron" [27]. And in a recent review of the treatment of anemia in pregnancy, Achebe and Gafter-Gvili [15] recommend intra- 
Fig. 1. Examples of physical signs of iron deficiency. a Cracking of the corners of the mouth (angular cheilosis). b Horizontal lines in the finger nails (Mees lines). c Depapillation of the tongue.
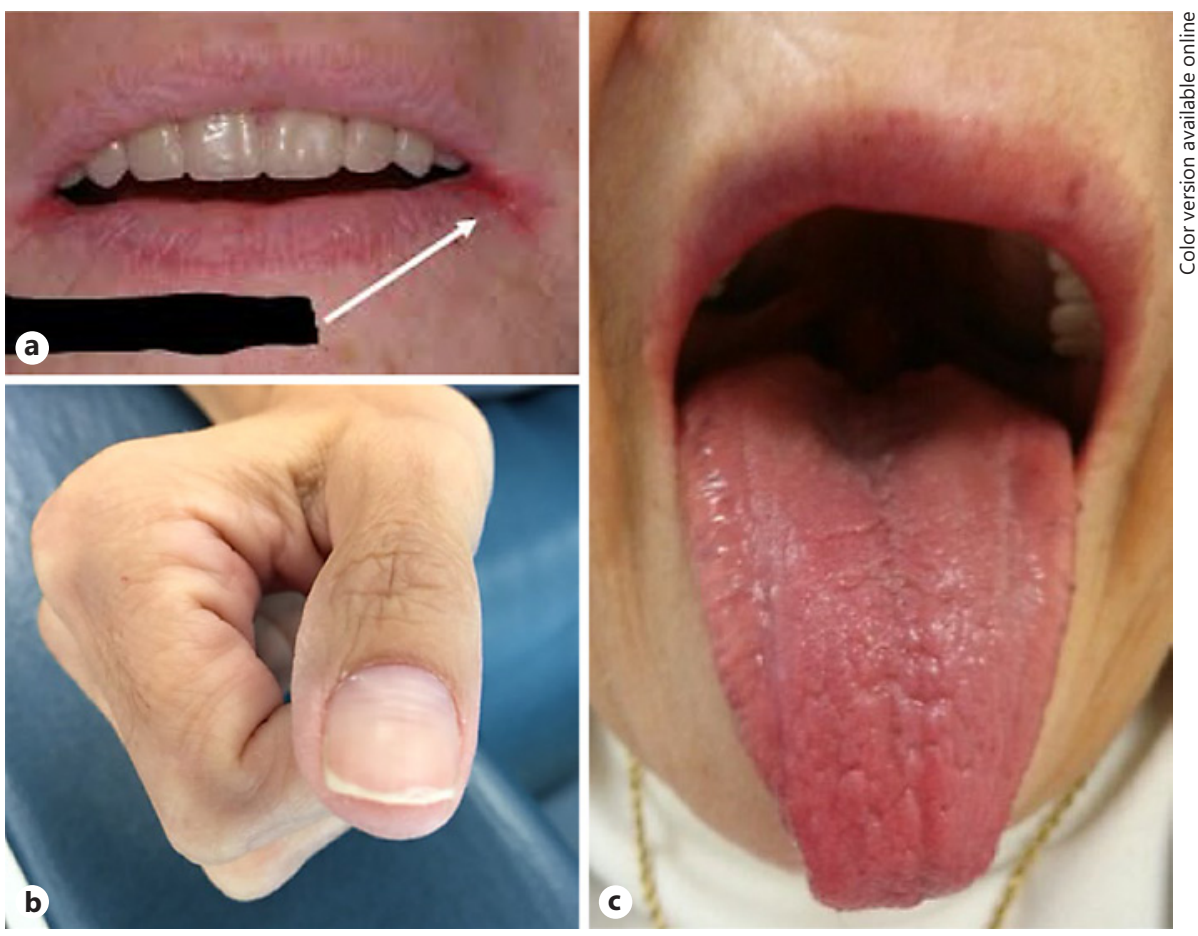

venous iron for any oral intolerant second- or third-trimester patient and for second-trimester gravidas with hemoglobin concentrations $<10.5 \mathrm{~g} / \mathrm{dL}$ and all in the third with IDA. There are no existing recommendations in either guideline for the treatment of nonanemic, ID pregnant women.

Why then is there such resistance for incorporating the early use of intravenous iron into the treatment paradigm of ID in pregnancy? We believe fear of serious adverse events (SAEs), including anaphylaxis, discourages obstetricians already struggling in a litigious environment. Misinterpretation of the nature of minor infusion reactions, such as serious hypersensitivity, further mitigates use. These minor reactions are due to labile free iron and consist of pressure in the chest or back or facial flushing - symptoms not seen with severe hypersensitivity. Further, premedication with antihistamines can cause somnolence, diaphoresis, tachycardia, and hypotension which may be attributed to the intravenous iron. Intervention with antihistamines or vasopressors can convert these minor reactions, which usually resolve in minutes without therapy, into hemodynamically significant SAEs, ostensibly due to the intravenous iron.

Older formulations of intravenous iron consisting of high-molecular-weight iron dextran, which are no longer available, were associated with an incidence of severe hy- persensitivity of 1-3\%. Newer formulations in the United States, Europe, and Asia (Table 1) include low-molecularweight iron dextran, ferric carboxymaltose, ferumoxytol (United States only), iron isomaltoside (Europe only), ferric gluconate, and iron sucrose. Iron dextran, ferric carboxymaltose, ferumoxytol, and iron isomaltoside are able to be administered as a complete replacement dose of $1,000 \mathrm{mg}$ in 15-60 min, while iron sucrose and ferric gluconate require 4-5 visits as doses of greater than 200-250 $\mathrm{mg}$ are proscribed due to a high incidence of infusion reactions and increased release of labile free iron from smaller carbohydrate cores that bind elemental iron less tightly [28]. Published safety and efficacy data for the second and third trimester have been reported with all of the formulations except for ferumoxytol. However, there are anecdotal reports of its safe and effective use in more than 200 gravidas [pers. commun., John Glaspy, UCLA], and one of the authors (M.A.) has treated more than 250 without an adverse event. A consistent theme in all the reports is absence of SAEs. Corroborating this observation is a meta-analysis of 103 trials comprising 10,391 patients treated with intravenous iron compared to 4,044 with oral, 1,329 no iron, 3,335 placebo, and 155 with intramuscular iron [29]. Parenthetically, intramuscular iron should be avoided as it is painful, requires multiple injections, stains the buttock, and is associated with gluteal sarcoma. 
Table 1. Intravenous iron preparations [40-45]

\begin{tabular}{|c|c|c|c|c|c|c|}
\hline Drug & Trade name & $\begin{array}{l}\text { Maximum approved dose, } \\
\text { mg elemental iron }\end{array}$ & $\begin{array}{l}\text { Total-dose } \\
\text { infusion } \\
\text { possible }\end{array}$ & Test dose & $\begin{array}{l}\text { Elemental iron } \\
\text { concentration, } \\
\mathrm{mg} / \mathrm{mL}\end{array}$ & Preservative \\
\hline Ferric gluconate [40] & Ferrlecit & 125 & No & No & 12.5 & Benzyl alcohol \\
\hline Iron sucrose [41] & Venofer & $200-300$ & No & No & 20 & None \\
\hline Ferumoxytol [42] & Feraheme & 510 & No & No & 30 & None \\
\hline Ferric carboxymaltose $[44]^{\mathrm{b}}$ & Ferinject & $20 \mathrm{mg} / \mathrm{kg}(\max 1,000 \mathrm{mg})$ & No & No & 50 & None \\
\hline
\end{tabular}

a The use of high-molecular-weight iron dextran preparations, rather than low-molecular-weight iron dextran preparations, is not recommended due to a higher incidence of adverse reactions. ${ }^{\mathrm{b}}$ Not available in the US. Common European trade name shown.

Overall, while uncommon infusion reactions were observed with intravenous iron, there was no increase in the risk of SAEs with intravenous iron compared to control, R 1.04 (95\% CI 0.93-1.17, 97 trials, $I^{2}=9 \%$ ) [29]. No difference in efficacy or toxicity among the formulations was observed consistent with all prospective [30-32], intrainstitutional retrospective studies [33] and meta-analyses [29].

\section{Use of Intravenous Iron in Pregnancy}

Nagai et al. [34] and Varde [35] in two different studies of intravenous iron in ID, reported safety and efficacy in $>2,000$ gravidas of complete replacement dosing with iron dextran in a single setting. Nearly ubiquitous efficacy was observed without any SAEs. Over 50 years later, the first United States prospective study of intravenous iron in pregnancy was published [14]. Seventy-four oral iron-intolerant, second- and third-trimester ID gravidas were questioned for oral iron intolerance and treated with intravenous iron, if present. All received $1,000 \mathrm{mg}$ of lowmolecular-weight iron dextran in $250 \mathrm{~mL}$ normal saline over $1 \mathrm{~h}$ without premedication unless multiple drug allergies or asthma were present, in which case methylprednisolone was administered prior to the test dose. Fifteen minutes after the test dose, the remainder was infused over the balance of $1 \mathrm{~h}$ if no infusion reactions were observed. Those enrolled were called at 1,2 , and 7 days to assess for delayed reactions. Four weeks post-infusion or postpartum, hemoglobin concentrations and iron parameters were measured. The mean pre- and post-hemoglobin concentrations were 9.7 and $10.8 \mathrm{~g} / \mathrm{dL}(p<$ $0.00001)$, and ferritins 14.5 and $126.3 \mathrm{ng} / \mathrm{mL}(p<$ 0.000001 ), respectively. While 6 experienced transient minor infusion reactions, all of which resolved without therapy, there were no SAEs. The authors concluded intravenous iron has less toxicity and is more effective than oral iron supporting moving it closer to frontline therapy [35].

An observational study of 189 consecutive, nonselected, oral iron-intolerant second- and third-trimester gravidas who received 1,000 $\mathrm{mg}$ of low-molecular-weight iron dextran over $1 \mathrm{~h}$ showed that hemoglobin concentrations increased by $1-1.9 \mathrm{~g} / \mathrm{dL}$ in $82 \%$ and by $\geq 2 \mathrm{~g} / \mathrm{dL}$ in $24 \%$. Anemia resolved in $95 \%$ of subjects, and no SAEs occurred. The authors concluded a large, single, rapidly administered dose of intravenous iron was effective, safe, and convenient [36].

Another prospective comparison of low-molecularweight iron dextran and ferric carboxymaltose reported a hemoglobin rise of $2.34-2.57 \mathrm{~g} / \mathrm{dL}$ at 4 weeks without any SAEs. The authors concluded that both formulations are effective and safe, with low risk of adverse events [31].

Subsequently, the British Blood Transfusion Society made the following recommendations in a consensus statement:

1 Obtain a full blood count to screen for anemia at presentation and at 28 weeks, as well as at any time during pregnancy if symptoms of anemia are present (evidence level 1A)

2 In women with microcytic or normocytic anemia, confirm ID by either a trial of oral iron or serum ferritin measurement (1B)

3 Consider intravenous iron for women with severe IDA (hemoglobin $<8 \mathrm{~g} / \mathrm{dL}$ ) or any newly diagnosed anemia beyond 34 weeks of gestation (1B)

4 Consider intravenous iron for women with confirmed IDA who fail to respond to or are intolerant of oral iron [37]. 


\section{Discussion/Conclusion}

While prospective outcome trials supporting the benefit of routine screening and iron supplementation with either intravenous or oral iron for pregnant women and neonates are lacking, high-quality evidence imputing a litany of morbid events associated with ID brings into question recommendations that fail to incorporate routine screening for ID of gravidas upon first presentation for prenatal care.

While awaiting prospective trials and based on the preponderance of published evidence supporting absence of harm of both screening and supplementation, we recommend the following:

1 Screen all gravidas for ID on presentation for prenatal care irrespective of hemoglobin levels

2 Administer iron supplementation if ID is present with or without anemia

3 Prescribe oral iron if ID is present the first trimester (we do not recommend intravenous iron in the first trimester due to a lack of safety data), and if ID persists, intravenous iron should be strongly considered once the pregnancy reaches the second trimester

4 If oral iron is prescribed, one tablet every other day is our recommendation

5 All high-risk neonates (including preterm infants, infants of diabetic mothers, infants born to anemic or iron deficient mothers, and infants of smokers) should be screened at birth for ID [38].

\section{Statement of Ethics}

The authors have no ethical conflicts to disclose.

\section{Disclosure Statement}

Dr. Juul: no conflicts of interest to declare. Dr. Derman: no conflicts of interest to declare. Dr. Auerbach has received research funding for data management from Pharmacosmos and AMAG Pharma.

\section{Funding Sources}

None.

\section{Author Contributions}

Dr. Juul was involved in the writing, editing, and design of the manuscript. Dr. Derman was involved in the conceptual framing of the manuscript, review of background literature, and editing of the manuscript. Dr. Auerbach was involved in the writing, editing, and design of the manuscript.

\section{References}

1 Cantor AG, Bougatsos C, Dana T, Blazina I, McDonagh M. Routine iron supplementation and screening for iron deficiency anemia in pregnancy: a systematic review for the U.S. Preventive Services Task Force. Ann Intern Med. 2015 Apr;162(8):566-76.

2 Daru J, Zamora J, Fernández-Félix BM, Vogel J, Oladapo OT, Morisaki N, et al. Risk of maternal mortality in women with severe anaemia during pregnancy and post partum: a multilevel analysis. Lancet Glob Health. 2018 May;6(5):e548-54.

3 Stevens GA, Finucane MM, De-Regil LM, Paciorek CJ, Flaxman SR, Branca F, et al.; Nutrition Impact Model Study Group (Anaemia). Global, regional, and national trends in haemoglobin concentration and prevalence of total and severe anaemia in children and pregnant and non-pregnant women for 1995-2011: a systematic analysis of population-representative data. Lancet Glob Health. 2013 Jul;1(1):e16-25.
4 Tran PV, Fretham SJ, Carlson ES, Georgieff MK. Long-term reduction of hippocampal brain-derived neurotrophic factor activity after fetal-neonatal iron deficiency in adult rats. Pediatr Res. 2009 May;65(5):493-8.

5 Zamora TG, Guiang SF 3rd, Widness JA, Georgieff MK. Iron is prioritized to red blood cells over the brain in phlebotomized anemic newborn lambs. Pediatr Res. 2016 Jun;79(6): 922-8.

6 Tran PV, Kennedy BC, Lien YC, Simmons RA, Georgieff MK. Fetal iron deficiency induces chromatin remodeling at the Bdnf locus in adult rat hippocampus. Am J Physiol Regul Integr Comp Physiol. 2015 Feb; 308(4):R276-82.

7 Shao J, Lou J, Rao R, Georgieff MK, Kaciroti N, Felt BT, et al. Maternal serum ferritin concentration is positively associated with newborn iron stores in women with low ferritin status in late pregnancy. J Nutr. 2012 Nov; 142(11):2004-9.
8 Congdon EL, Westerlund A, Algarin CR, Peirano PD, Gregas M, Lozoff B, et al. Iron deficiency in infancy is associated with altered neural correlates of recognition memory at 10 years. J Pediatr. 2012 Jun;160(6):1027-33.

9 Lozoff B, Jimenez E, Smith JB. Double burden of iron deficiency in infancy and low socioeconomic status: a longitudinal analysis of cognitive test scores to age 19 years. Arch Pediatr Adolesc Med. 2006 Nov;160(11):110813.

10 Lozoff B. Iron deficiency and child development. Food Nutr Bull. 2007 Dec;28(4 Suppl):S560-71.

11 Drukker L, Hants Y, Farkash R, Ruchlemer R, Samueloff A, Grisaru-Granovsky S. Iron deficiency anemia at admission for labor and delivery is associated with an increased risk for Cesarean section and adverse maternal and neonatal outcomes. Transfusion. 2015 Dec; 55(12):2799-806. 
12 Centers for Disease Control and Prevention. Recommendations to prevent and control iron deficiency in the United States. MMWR 1998;47(RR-3):1-29.

13 Zimmermann MB, Burgi H, Hurrell RF. Iron deficiency predicts poor maternal thyroid status during pregnancy. J Clin Endocrinol Metab. 2007 Sep;92(9):3436-40.

14 Auerbach M, James SE, Nicoletti M, Lenowitz S, London N, Bahrain HF, et al. Results of the First American Prospective Study of Intravenous Iron in Oral Iron-Intolerant Iron-Deficient Gravidas. Am J Med. 2017 Dec;130(12): $1402-7$.

15 Achebe MM, Gafter-Gvili A. How I treat anemia in pregnancy: iron, cobalamin, and folate. Blood. $2017 \mathrm{Feb}$;129(8):940-9.

16 Scholl TO. Maternal iron status: relation to fetal growth, length of gestation, and iron endowment of the neonate. Nutr Rev. 2011 Nov; 69 Suppl 1:S23-9.

17 Johnson S, Lang A, Sturm M, O'Brien SH. Iron Deficiency without Anemia: A Common Yet Under-Recognized Diagnosis in Young Women with Heavy Menstrual Bleeding. J Pediatr Adolesc Gynecol. 2016 Dec;29(6):62831.

18 Lorenz L, Peter A, Poets CF, Franz AR. A review of cord blood concentrations of iron status parameters to define reference ranges for preterm infants. Neonatology. 2013;104(3): 194-202.

19 Cusick SE, Georgieff MK, Rao R. Approaches for Reducing the Risk of Early-Life Iron Deficiency-Induced Brain Dysfunction in Children. Nutrients. 2018 Feb;10(2):10.

20 German K, Vu PT, Grelli KN, Denton C, Lee G, Juul SE. Zinc Protoporphyrin-to-Heme Ratio and Ferritin as Measures of Iron Sufficiency in the Neonatal Intensive Care Unit. J Pediatr. 2018 Mar; 194:47-53.

21 Siddappa AM, Rao R, Long JD, Widness JA, Georgieff MK. The assessment of newborn iron stores at birth: a review of the literature and standards for ferritin concentrations. Neonatology. 2007;92(2):73-82.

22 Lorenz L, Arand J, Büchner K, Wacker-Gussmann A, Peter A, Poets CF, et al. Reticulocyte haemoglobin content as a marker of iron deficiency. Arch Dis Child Fetal Neonatal Ed. 2015 May; 100(3):F198-202.

23 WHO: Iron deficiency anaemia: assessment, prevention and control. WHO/NHD/01.3. Geneva: WHO; 2001.

24 Moretti D, Goede JS, Zeder C, Jiskra M, Chatzinakou V, Tjalsma H, et al. Oral iron supplements increase hepcidin and decrease iron absorption from daily or twice-daily doses in iron-depleted young women. Blood. 2015 Oct;126(17):1981-9.
25 Stoffel NU, Cercamondi CI, Brittenham G, Zeder C, Geurts-Moespot AJ, Swinkels DW, et al. Iron absorption from oral iron supplements given on consecutive versus alternate days and as single morning doses versus twice-daily split dosing in iron-depleted women: two open-label, randomised controlled trials. Lancet Haematol. 2017 Nov; 4(11):e524-33.

26 American College of Obstetricians and Gynecologists. ACOG Practice Bulletin No. 95: anemia in pregnancy. Obstet Gynecol. 2008 Jul;112(1):201-7.

27 Pavord S, Myers B, Robinson S, Allard S, Strong J, Oppenheimer C; British Committee for Standards in Haematology. UK guidelines on the management of iron deficiency in pregnancy. Br J Haematol. 2012 Mar;156(5): 588-600.

28 Jahn MR, Andreasen HB, Fütterer S, Nawroth T, Schünemann V, Kolb U, et al. A comparative study of the physicochemical properties of iron isomaltoside 1000 (Monofer), a new intravenous iron preparation and its clinical implications. Eur J Pharm Biopharm. 2011 Aug;78(3):480-91.

29 Avni T, Bieber A, Grossman A, Green H, Leibovici L, Gafter-Gvili A. The safety of intravenous iron preparations: systematic review and meta-analysis. Mayo Clin Proc. 2015 Jan; 90(1):12-23.

30 Sav T, Tokgoz B, Sipahioglu MH, Deveci M, Sari I, Oymak O, et al. Is there a difference between the allergic potencies of the iron sucrose and low molecular weight iron dextran? Ren Fail. 2007;29(4):423-6.

31 Myers B, Myers O, Moore J. Comparative efficacy and safety of intravenous ferric carboxymaltose (Ferinject) and iron(III) hydroxide dextran (Cosmofer) in pregnancy. Obstet Med. 2012 Sep;5(3):105-7.

32 Hetzel D, Strauss W, Bernard K, Li Z, Ur boniene A, Allen LF. A Phase III, randomized, open-label trial of ferumoxytol compared with iron sucrose for the treatment of iron deficiency anemia in patients with a history of unsatisfactory oral iron therapy. Am J Hematol. 2014 Jun;89(6):646-50.

33 Okam MM, Mandell E, Hevelone N, Wentz R, Ross A, Abel GA. Comparative rates of adverse events with different formulations of intravenous iron. Am J Hematol. 2012 Nov; 87(11):E123-4.
34 Nagai A, Nakagawa E, Choi HB, Hatori K, Kobayashi S, Kim SU. Erythropoietin and erythropoietin receptors in human CNS neurons, astrocytes, microglia, and oligodendrocytes grown in culture. J Neuropathol Exp Neurol. 2001 Apr;60(4):386-92.

35 Varde KN. Treatment of 300 cases of iron deficiency of pregnancy by total dose infusion of iron-dextran complex. J Obstet Gynaecol Br Commonw. 1964 Dec;71(6):919-22.

36 Wong L, Smith S, Gilstrop M, Derman R, Auerbach S, London N, et al. Safety and efficacy of rapid (1,000 $\mathrm{mg}$ in $1 \mathrm{hr}$ ) intravenous iron dextran for treatment of maternal iron deficient anemia of pregnancy. Am J Hematol. 2016 Jun;91(6):590-3.

37 Munoz M, Pena-Rosas JP, Robinson S, Milman N, Holzgreve W, Breymann C, et al. Patient blood management in obstetrics: management of anaemia and haematinic deficiencies in pregnancy and in the post-partum period: NATA consensus statement. Transfus Med. 2018 Feb;28(1):22-39.

38 MacQueen BC, Christensen RD, Ward DM, Bennett ST, O’Brien EA, Sheffield MJ, et al. The iron status at birth of neonates with risk factors for developing iron deficiency: a pilot study. J Perinatol. 2017 Apr;37(4):436-40.

39 INFeD (iron dextran) US prescribing information (revision September 2009). Available at: https://dailymed.nlm.nih.gov/dailymed/ drugInfo.cfm? setid=abacb $7 \mathrm{fa}-2 \mathrm{fc} 2-471 \mathrm{e}-$ 9200-944eeac8ca2a.

40 Ferrlecit (sodium ferric gluconate complex in sucrose) US prescribing information (revision August 2011). Available at: https://dailymed.nlm.nih.gov/dailymed/drugInfo. cfm?setid=1fe028ff-42ac-4329-b1a5-a9dadfcb79f6.

41 Venofer (iron sucrose) US prescribing information (revision September 2012). Available at: https://dailymed.nlm.nih.gov/dailymed/ drugInfo.cfm? setid=f1 ab 1 a $22-2$ b $99-4$ d 27 8b5a-9c3bcd5e3040.

42 Feraheme (ferumoxytol) US prescribing information (revision June 2011). Available at: https://dailymed.nlm.nih.gov/dailymed/drugInfo.cfm?setid=32b0e320-a739-11dc-a704$0002 \mathrm{a} 5 \mathrm{~d} 5 \mathrm{c} 51 \mathrm{~b}$

43 Monofer (iron [III] isomaltoside 1000) United Kingdom summary of product characteristics (revision June 1, 2012). Available at: https://www.medicines.org.uk/emc/product/5676.

44 Ferinject (ferric carboxymaltose) United Kingdom summary of product characteristics (revision October 2011). Available at: https:// www.medicines.org.uk/emc/product/5910. 